Locke's political liberty: readings and misreadings, Edited by Christophe Miqueu and Mason Chamie

\title{
Maurizio Melai
}

\section{(2) OpenEdition}

\section{Journals}

\section{Edizione digitale}

URL: http://journals.openedition.org/studifrancesi/6646

DOI: $10.4000 /$ studifrancesi.6646

ISSN: 2421-5856

Editore

Rosenberg \& Sellier

\section{Edizione cartacea}

Data di pubblicazione: 1 septembre 2010

Paginazione: 369-370

ISSN: 0039-2944

\section{Notizia bibliografica digitale}

Maurizio Melai, «Locke's political liberty: readings and misreadings, Edited by Christophe Miqueu and

Mason Chamie», Studi Francesi [Online], 161 (LIV | II) | 2010, online dal 30 novembre 2015, consultato il

12 janvier 2021. URL: http://journals.openedition.org/studifrancesi/6646 ; DOI: https://doi.org/

10.4000/studifrancesi.6646

Questo documento è stato generato automaticamente il 12 janvier 2021.

\section{(c) $(1)(8)$}

Studi Francesi è distribuita con Licenza Creative Commons Attribuzione - Non commerciale - Non opere derivate 4.0 Internazionale. 


\title{
Locke's political liberty: readings and misreadings, Edited by Christophe Miqueu and Mason Chamie
}

\author{
Maurizio Melai
}

\section{NOTIZIA}

Locke's political liberty: readings and misreadings, Edited by Christophe MIQUEU and Mason CHAMIE, Oxford, Voltaire Foundation, 2009 (SVEC 2009:04), pp. 229.

1 La presente raccolta di studi si prefigge l'obiettivo di mettere in luce alcuni aspetti inediti della ricezione della filosofia politica di John Locke. Non accontentandosi della visione schematica e semplicistica che designa Locke come padre del Liberalismo moderno, il volume intende soffermarsi in particolare sulle molteplici ed eterogenee interpretazioni di cui è stata oggetto, nel corso del Settecento ed oltre, la concezione lockiana della libertà politica.

2 La prima delle due sezioni che compongono il volume, intitolata «From resistance to toleration", si apre con un articolo di Jean TERREL, Constituent power and resistance: did Locke have any followers? (pp. 13-33). Toccando le tematiche cardine della filosofia politica lockiana, Terrel rileva che la grande questione dell'instabilità del potere che si nasconde dietro le celebri teorie della legge naturale e del patto di associazione alla base della formazione dello stato civile sembra esser stata trascurata dai seguaci settecenteschi e dagli studiosi moderni del pensiero del filosofo inglese. Lo studio di Pierre LURBE che segue (Political liberty in John Toland's "Anglia Libera“, pp. 35-49) mostra la tendenziosità della lettura dei trattati politici di Locke proposta da Toland, lettura volta alla giustificazione della Gloriosa Rivoluzione e messa al servizio di un'ideologia repubblicana ben poco lockiana. I tre articoli successivi, che completano la prima sezione del volume, istituiscono un confronto tra Locke e tre grandi filosofi del Settecento, rispettivamente Shaftesbury, Rousseau e Voltaire, sul tema fondamentale 
della tolleranza religiosa. Mentre l'articolo di Daniel CAREY (Two strategies on toleration: Locke, Shaftesbury and diversity, pp. 51-67) indica il concetto di diversità come punto di convergenza tra il pensiero politico-religioso di Locke e quello di Shaftesbury, lo studio di Christopher BROоKE «Locke en particulier les a traitées exactement dans les mêmes principes que moi»: revisiting the relationship between Locke and Rousseau, pp. 69-82) rileva l'impronta lockiana delle Lettres écrites de la montagne di Rousseau. Gerhardt STENGER, infine, nell'articolo Liberty and toleration: Locke, Voltaire and «laïcité à la française» (pp. 83-94), mostra come Voltaire giunga al relativismo religioso attraverso l'epistemologia lockiana e la sua affermazione dell'impossibilità della conoscenza umana.

Nel saggio The propriety of liberty and the quality of responsible agency (pp. 97-125), che apre la seconda sezione della raccolta (intitolata «From propriety to property»), Duncan KELLY prende in esame il significato che Locke conferisce al concetto di libertà: negli scritti del filosofo inglese la libertà, concepita come responsabilità individuale, non può far sì che l'individuo venga meno al controllo delle passioni nella sfera privata ed alla moderazione dei giudizi nella sfera pubblica. L'articolo seguente, di Pierre-Yves QUIVIGER (Sieyès as a reader of John Locke: metaphysics, politics and law, pp. 127-142), si sofferma sulle riflessioni di Sieyès, grande ammiratore di Locke, a proposito di alcune delle principali teorie politiche formulate dall'autore dell'Essay concerning human understanding, ed in particolare riguardo alle questioni della comunità pre-legale, della divisione dei poteri, della proprietà come libertà e dell'anti-paternalismo.

La mancata diffusione delle opere politiche di Locke in Danimarca, tradotte in danese solo a partire dagli anni Novanta del secolo scorso, è oggetto delle riflessioni condotte da Jørn SCHøSLER nell'articolo intitolato The reception of Lockes's political philosophy in Denmark: an historical approach (pp. 143-163), mentre lo studio di Jean-Fabien SPITZ (Nozick's "Locke on property": an obituary, pp. 189-207) denuncia l'errore in cui incorrono tutti quegli interpreti di Locke che, alla stregua di Nozick, vedono nel filosofo inglese il paladino del diritto incondizionato alla proprietà privata. Jamers FARR (Locke, natural law and New World slavery, pp. 165-188) si sofferma infine su un episodio assai controverso della vita di John Locke, un episodio che rischia di incrinare l'immagine di campione della libertà comunemente associata al nome del filosofo, ovvero l'appoggio che egli accordò alla pratica della schiavitù in America. 